\title{
Development of a food composition database for the estimation of dietary intakes of glucosinolates, the biologically active constituents of cruciferous vegetables
}

\author{
S. A. McNaughton ${ }^{1,2 *}$ and G. C. Marks ${ }^{1}$ \\ ${ }^{1}$ Nutrition Program, School of Population Health, University of Queensland, Herston, Queensland, 4029, Australia
}

(Received 19 April 2002 - Revised 21 March 2003 - Accepted 22 April 2003)

\begin{abstract}
Evidence indicates that cruciferous vegetables are protective against a range of cancers with glucosinolates and their breakdown products considered the biologically active constituents. To date, epidemiological studies have not investigated the intakes of these constituents due to a lack of food composition databases. The aim of the present study was to develop a database for the glucosinolate content of cruciferous vegetables that can be used to quantify dietary exposure for use in epidemiological studies of diet-disease relationships. Published food composition data sources for the glucosinolate content of cruciferous vegetables were identified and assessed for data quality using established criteria. Adequate data for the total glucosinolate content were available from eighteen published studies providing 140 estimates for forty-two items. The highest glucosinolate values were for cress $(389 \mathrm{mg} / 100 \mathrm{~g})$ while the lowest values were for Pe-tsai chinese cabbage $(20 \mathrm{mg} / 100 \mathrm{~g})$. There is considerable variation in the values reported for the same vegetable by different studies, with a median difference between the minimum and maximum values of $5 \cdot 8$-fold. Limited analysis of cooked cruciferous vegetables has been conducted; however, the available data show that average losses during cooking are approximately $36 \%$. This is the first attempt to collate the available literature on the glucosinolate content of cruciferous vegetables. These data will allow quantification of intakes of the glucosinolates, which can be used in epidemiological studies to investigate the role of cruciferous vegetables in cancer aetiology and prevention.
\end{abstract}

Glucosinolates: Cruciferous vegetables: Food composition database: Dietary intake: Cancer

A high dietary intake of cruciferous vegetables has been consistently associated with protection against a range of cancers (Verhoeven et al. 1996). In the most comprehensive review to date of the epidemiological evidence for a link between cruciferous vegetables and cancer, five of the seven cohort studies identified reported an inverse association between the consumption of at least one or more cruciferous vegetables and cancer risk (Verhoeven et al. 1996). Of a total of eighty-seven case-control studies, sixty-eight found a lower risk of cancer associated with the consumption of cruciferous vegetables (Verhoeven et al. 1996). According to this review, the strongest evidence so far is for an effect in cancers of the digestive and respiratory tracts with less consistent results for the hormone-dependent cancers, although fewer studies have been reported (Verhoeven et al. 1996).

The largest and most commonly consumed group of edible plants within the family Cruciferae are the vegetables of the Brassica genus. The Brassica vegetables include cabbage (red, white and savoy), Brussels sprouts, broccoli, cauliflower, turnip, swede (or rutabaga), kohlrabi, kale, collard, Chinese kale, mustard (black, brown and
Abyssian) and Chinese cabbage (Nugon-Baudon \& Rabot, 1994). Other edible plants of the Cruciferae family include white mustard, sea kale, radish, horseradish, wasabi (Japanese horseradish), salad rocket, garden cress and watercress (Nugon-Baudon \& Rabot, 1994).

Cruciferous vegetables contain a range of potentially anti-carcinogenic dietary factors including carotenoids, vitamin C, fibre, flavonoids and glucosinolates (Steinmetz \& Potter, 1991). Importantly, glucosinolates are present in almost every member of the Cruciferae family (McGregor et al. 1983) and the presence of glucosinolates distinguishes cruciferous vegetables from other vegetables (Van Poppel et al. 1999). Tiedink et al. (1988) analysed approximately thirty different vegetables including a range of cruciferous vegetables such as cauliflower, Brussels sprouts, savoy cabbage, broccoli, red cabbage, green cabbage, oxheart cabbage, white cabbage, kohlrabi, Chinese cabbage, swede, radish and horseradish. A range of other non-cruciferous vegetables were also investigated including French beans, slicing beans, fava beans, peas, marrowfat peas, endive, chicory, spinach, lettuce, onion, leek, red beet, carrots, green pepper, red pepper, tomato,

* Corresponding author: Ms S. A. McNaughton, present address MRC Human Nutrition Research, Elsie Widdowson Laboratory, Fulbourn Road, Cambridge CB1 9NL, UK, fax +44 1223 437515, email Sarah.Mcnaughton@mrc-hnr.cam.ac.uk 
cucumber and mushroom. Only the cruciferous vegetables were shown to contain glucosinolates. However, three noncruciferous edible plants have also been shown to contain glucosinolates (Nugon-Baudon \& Rabot, 1994). These are capers, papaya (pawpaw) and nasturtium (Indian cress). The contribution of these plants to glucosinolate intake will vary according to the specific dietary habits of different populations.

Glucosinolates undergo hydrolysis to isothiocyanates and indoles upon contact with the enzyme myrosinase, which is present within the plant tissues (Verhoeven et al. 1997). Experimental studies show that these breakdown products possess a number of anti-carcinogenic activities such as induction of xenobiotic-metabolising enzymes, suppression of cancer expression, and inhibition of DNA methylation (Jongen, 1996; World Cancer Research Fund, 1997; Van Poppel et al. 1999; Talalay \& Fahey, 2001). As with glucosinolates, these breakdown products have not been detected in non-cruciferous vegetables such as lettuce, spinach, green beans and snow peas (Jiao et al. 1998).

In a recent review, Crews et al. (2001) highlighted the lack of food composition tables for glucosinolates and the resultant difficulties in conducting epidemiological and dietary intake studies of these compounds in populations. To date, epidemiological studies investigating the cancer-protective activity of constituents of cruciferous vegetables have relied on quantifying exposure based on the weight or servings of cruciferous vegetable consumed. This approach has limitations in that the levels of glucosinolates vary between different cruciferous vegetables and it does not account for different consumption patterns between individuals (Nugon-Baudon \& Rabot, 1994). The aim of the present study was to develop a database for the glucosinolate content of cruciferous vegetables that can be used to quantify dietary exposure for use in epidemiological studies investigating diet-disease relationships and overcome some of the limitations of previous studies.

A wide range of individual glucosinolates, isothiocyanates and indoles could have been quantified for the development of this food composition database. However, as research in this area is still progressing it is unclear which of the individual compounds are most important with regard to cancer-protective activity. The intake of total glucosinolates represents a biologically relevant exposure and encompasses exposure to a variety of related compounds with similar biological actions. The use of total glucosinolate intake relies on the assumption that the total glucosinolate content of the cruciferous vegetables is related to the content of hydrolysis products with anti-carcinogenic potential (i.e. isothiocyanates and indoles).

\section{Methods}

A literature search was conducted using Medline (United States National Library of Medicine, 2000) and CAB Abstracts (CAB International, 2000) to identify possible sources of published food composition data for glucosinolates. The search terms included cruciferous vegetables, brassica vegetables, glucosinolates, isothiocyanates, indoles, food composition, food and diet. Papers were identified that contained quantitative data on the total glucosinolate levels in cruciferous vegetables eaten by human consumers. Papers that only included qualitative analysis or glucosinolate profiles (that is, identification of glucosinolate compounds rather than quantifying amounts) were excluded. Papers that only measured a specific glucosinolate compound and did not report total glucosinolates were also excluded. Appropriate methods of analysis included measurement of total glucosinolates by the glucose-release method or the measurement of intact glucosinolates by HPLC or GC. Evidence shows that estimation of total glucosinolates using these methods is considered comparable (Ciska et al. 1994; Ciska \& Kozlowska, 1998; Hrncirik et al. 1998). Review papers that contained no new primary data were also excluded; however, the citations used in these reviews were crosschecked with initial literature searching and any additional references were identified.

Each study was considered using established criteria (Rand et al. 1987). These criteria have been used in the establishment of food composition databases for other non-nutrient dietary factors such as the United States Department of Agriculture-Nutrition Coordinating Center carotenoid database (United States Department of Agriculture, 1998), the United States Department of AgricultureIowa State University isoflavones database (United States Department of Agriculture and Iowa State University, 2000) and the development of a flavonoid database (Peterson \& Dwyer, 2000). The five criteria categories by which the studies were assessed are the analytical method used, the number of samples, the sample handling procedures, the sampling plan for selection of foods and the analytical quality control. These criteria have previously been used to calculate formal scores or ratings of data quality; however, in this context due to the relatively small number of studies available, the criteria were used to qualitatively review and compare the studies.

Initially, twenty-seven studies were identified that contained primary quantitative analysis of total glucosinolates for edible cruciferous vegetables. These studies were reviewed in order to assess comparability of data. To allow for comparison across all studies, amounts of total glucosinolates were converted to $\mathrm{mg} / 100 \mathrm{~g}$ fresh weight. Values that were expressed on a dry-weight basis were converted to a fresh-weight basis using the reported moisture content or by assuming an expected moisture content based on literature values (National Food Authority, 1995). When glucosinolate values were expressed as $\mu \mathrm{mol} / 100 \mathrm{~g}$, the average molecular weight of glucosinolates as reported in the study was used in the conversion to $\mathrm{mg} / 100 \mathrm{~g}$ based on the appropriate equation $(\mathrm{mol}=$ mass $/$ molecular weight $)$. If the study did not report a molecular weight, it was excluded from the database (Carlson et al. 1981; Tiedink et al. 1988; De Groot et al. 1991; Shattuck et al. 1991; Rosa \& Heaney, 1993; Shattuck \& Wang, 1994; Hansen et al. 1997; Kushad et al. 1999; Rodrigues \& Rosa, 1999). Data expressed as $\mathrm{mg} / \mathrm{kg}$ and parts per million were also converted to mg/100 g (Daxenbichler et al. 1979; Lewis \& Fenwick, 1988). If studies involved investigation of the effects of a treatment on glucosinolate composition, then only data 
from control groups that represented standard growing conditions were considered. A number of studies only provided a single mean value for all cultivars whereas some studies presented individual data for each cultivar that was analysed and so in order to maintain consistency a mean value was calculated for these studies and used in the aggregation of data.

Data for identical foods from separate references were aggregated. The vegetables were grouped on the basis of the common name description and the scientific name of the vegetable where provided. Alternate common names for identical or similar foods were confirmed using appropriate references (Rogers, 1995; Conran et al. 1997). Both mean and median values were calculated where multiple references provided data in order to assess the effect of extreme values of the aggregated value. The median value has been presented in the database as some mean values were adversely affected by extreme values. The median has been commonly used when compiling food composition data from a limited number of studies (Mangels et al. 1993; Reinli \& Block, 1996; Pillow et al. 1999).

\section{Results}

Glucosinolate values from eighteen studies were used for collation of the final database values. A summary of the important aspects of these studies including country or region of the study, the foods analysed, the analytical method, number of cultivars or samples analysed are presented in Table 1. The total glucosinolate content from all references considered for all edible vegetables of the Cruciferae family and the aggregated data are presented in Table 2.

Limited analysis of cooked cruciferous vegetables has been conducted. This resulted in a small number of studies contributing the cooked values for vegetables and in all cases, except cooked Brussels sprouts, values for cooked foods were determined by only one study. Table 3 presents the results of studies that have analysed cruciferous vegetables in both cooked and raw forms. This provides comparable data for the assessment of cooking losses and may be useful when trying to attribute total glucosinolate values for cooked vegetables where no data exist. The decrease in glucosinolate content due to cooking ranges from 18.1 to $59.2 \%$ with a mean decrease of $35.7 \%$.

\section{Discussion}

This is the first attempt to summarise the available literature on the glucosinolate content of cruciferous vegetables. Previously, a number of review papers have compared results of the glucosinolate content of cruciferous vegetables but have not collated data from multiple studies to provide single estimates (McDanell et al. 1988; Nugon-Baudon \& Rabot, 1994; Jongen, 1996).

The most common method for the measurement of total glucosinolates is based on colorimetric determination of enzymically released glucose. This method is based on the fact that when glucosinolates undergo hydrolysis, equimolar amounts of glucose are produced (De Vos \&
Blijleven, 1988; McDanell et al. 1988; Griffiths et al. 1998). Importantly, the production of glucose occurs regardless of the glucosinolate precursor and the conditions of hydrolysis (Fenwick et al. 1983). The glucose-release method was used by many of the studies included in the present review although separation and quantification of glucosinolates via HPLC and GC have also become popular (McGregor et al. 1983; Griffiths et al. 1998; Hrncirik et al. 1998). Evidence shows that these methods are comparable for the estimation of total glucosinolates (Ciska et al. 1994; Ciska \& Kozlowska, 1998; Hrncirik et al. 1998).

The majority of literature concerning the glucosinolate content of cruciferous vegetables tends to include only fresh vegetables; however, this may have limited relevance considering that many of these vegetables are consumed after cooking (Heaney et al. 1985; De Vos \& Blijleven, 1988). It has been suggested that calculating estimates of glucosinolate intake on values obtained from fresh vegetables provides an indication of the maximum possible intake of glucosinolates (Heaney et al. 1985). However, determining intakes based on the proportion of cruciferous vegetables eaten raw or cooked may allow better separation of individuals according to intake rather than treating all cruciferous vegetable intake as fresh.

Glucosinolates are lost from vegetables during processing such as storage, cutting and cooking (Heaney et al. 1985; De Vos \& Blijleven, 1988; Verkerk et al. 1997). The data available from the present study suggest that average losses during cooking are approximately $36 \%$ (for vegetables such as Brussels sprouts, cabbage, cauliflower, swede, turnip). Dekker et al. (2000) provide an approach to modelling the effects of cooking on the glucosinolate content of cruciferous vegetables, which is dependent on temperature used, the amount of cooking water used and the cooking time. It would be possible to apply this process to the raw food values using the cooking practices of the individual or population under investigation to account for cooking losses and their impact on the intake of glucosinolates.

Glucosinolates and their breakdown products are watersoluble compounds and it has been suggested that loss of glucosinolates during cooking is due to leaching into the cooking water (De Vos \& Blijleven, 1988; Verkerk et al. 1997), although at least some of the loss of glucosinolates is due to degradation (Heaney et al. 1985). It has been shown that the level of leaching into the cooking water is more strongly related to the amount of cooking water used rather than the cooking time or method (Dekker et al. 2000).

It appears that not all processing results in a decrease in the content of glucosinolates. Verkerk et al. (2001) found that chopping and storage of cabbage leads to increased levels of some individual glucosinolates and similar results have also been shown for broccoli (Rodrigues \& Rosa, 1999). Therefore, two opposing processes may be underway within the vegetables, which will affect the final content of glucosinolates in the consumed product.

Jiao et al. (1998) conducted studies measuring isothiocyanates in cruciferous vegetables before and after cooking. In eighty-two samples of cruciferous vegetables 


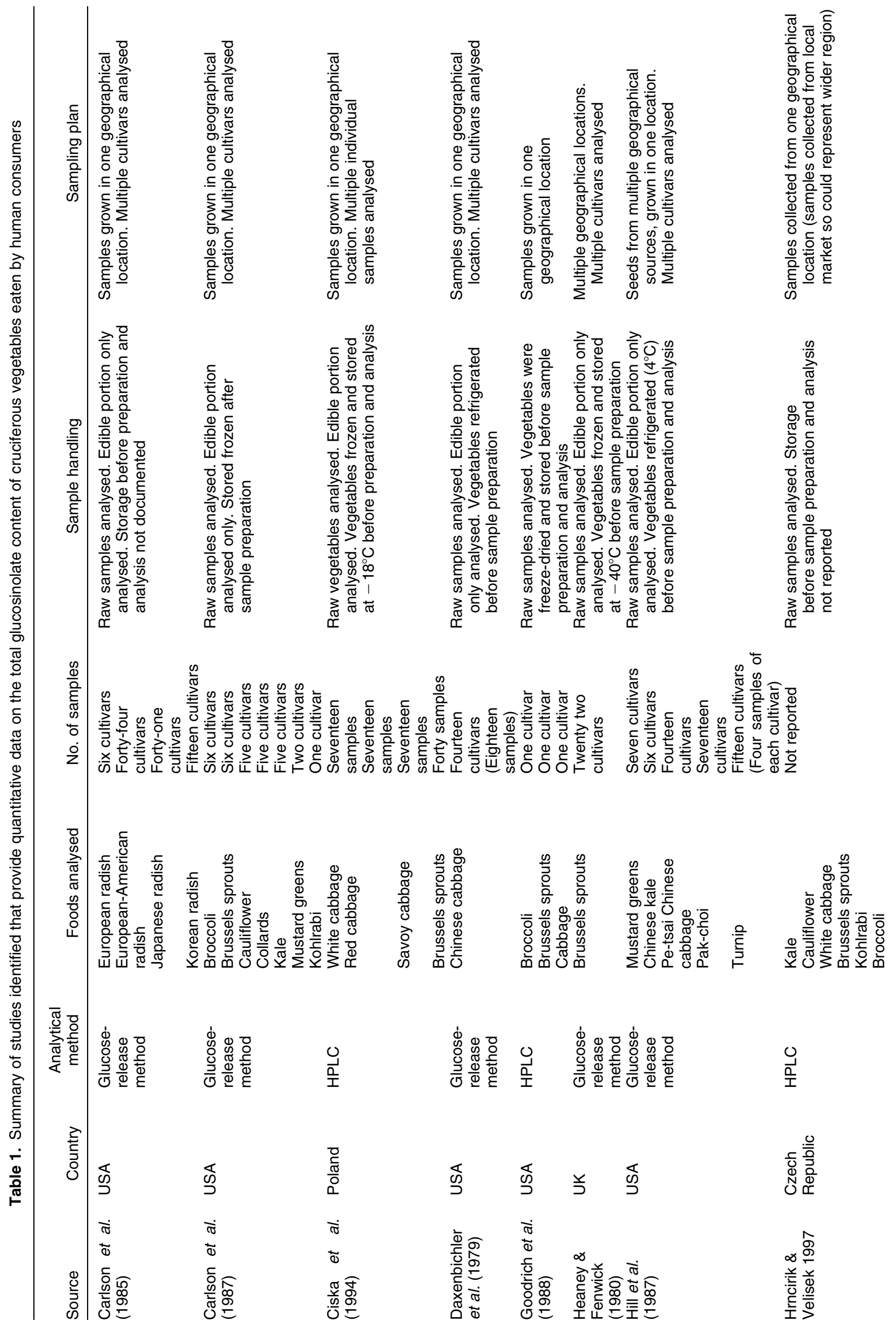


Glucosinolate content of cruciferous vegetables

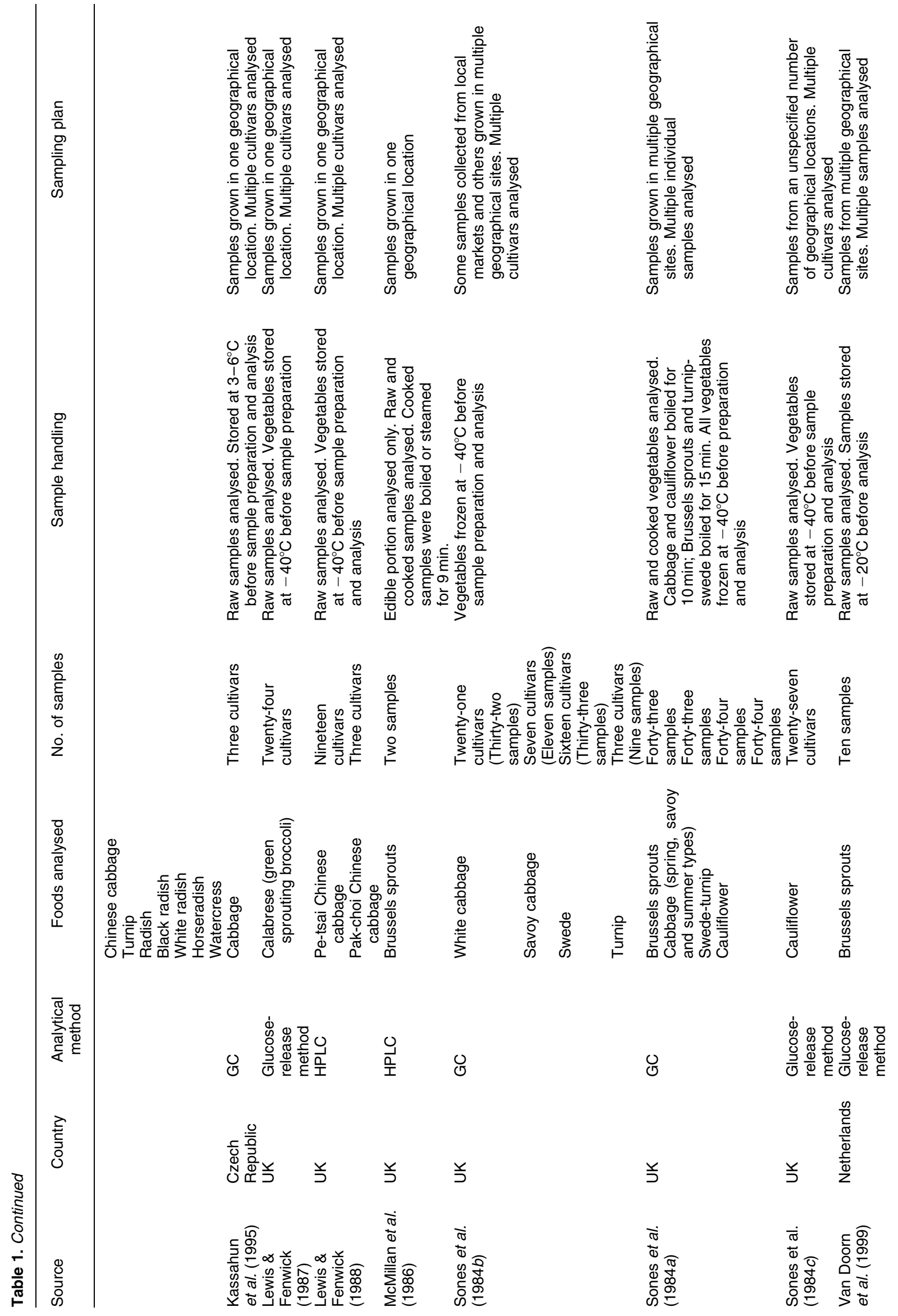


(nine different types), only three (two from kai choi and one from watercress) were found to contain detectable amounts of isothiocyanates after cooking. However, the amount of isothiocyanates found in these three cooked samples was very small compared with samples that had been cooked and subject to myrosinase hydrolysis (0.4-0.6 v. 71.2-81.3 $\mu \mathrm{mol} / 100 \mathrm{~g}$ wet weight). This has confirmed previous reports that breakdown products of glucosinolates were not detectable in cooked cruciferous vegetables (De Vos \& Blijleven, 1988). This would suggest that glucosinolates rather than their degradation products are consumed when cooked cruciferous vegetables are eaten (Jiao et al. 1998).

The research mentioned earlier suggests that only very small amounts of hydrolysis breakdown products, if any, are found in cooked cruciferous vegetables. The probable effect of the presence of these biologically active breakdown products, if the total glucosinolate content of cruciferous vegetables is used as the measured exposure, is to increase the exposure measurement error. However, it could be expected that this source of measurement error would occur equally for cases and controls and therefore could be interpreted as non-differential measurement error. This would result in attenuation of the diet-disease relationship rather than an alteration in the direction of the relationship (Armstrong et al. 1992).

Getahun \& Chung (1999) found that when cooked watercress was consumed, despite the complete inactivation of myrosinase in the vegetable, glucosinolates were converted to their biologically active breakdown products and it is suggested that microflora within the intestinal tract are responsible. The metabolism and conversion of glucosinolates to isothiocyanates determines the extent and overall rate of uptake in man (Shapiro et al. 1998). However, it has been shown that the bioavailability of the isothiocyanate breakdown products is lower when intact glucosinolates in the diet are consumed compared with pre-hydrolysed glucosinolates (Dekker et al. 2000).

There is considerable variation in the glucosinolate composition of cruciferous vegetables as shown by the range of values provided by the individual studies. The median difference between the minimum and maximum values reported by different studies for the same food was $5 \cdot 8$-fold. This variation represents true variation due to the measurement of different cultivars of particular vegetables and different growing conditions such as soil, climate and cultivation practices but it may also represent some inter-laboratory variation in methodology.

The consumption of cruciferous vegetables (for example, in servings per day) could serve as a proxy measure for glucosinolate consumption; however, quantification of glucosinolates provides an improvement in the measurement of exposure. First, not all cruciferous vegetables contain equal amounts of glucosinolates and both the amounts and types of cruciferous vegetables that are consumed have been shown to vary across countries and within population groups (Nugon-Baudon \& Rabot, 1994). For example, as income increases, there is an increase in the total fresh green vegetable consumption and a preference for milder-flavoured cruciferous 
Glucosinolate content of cruciferous vegetables

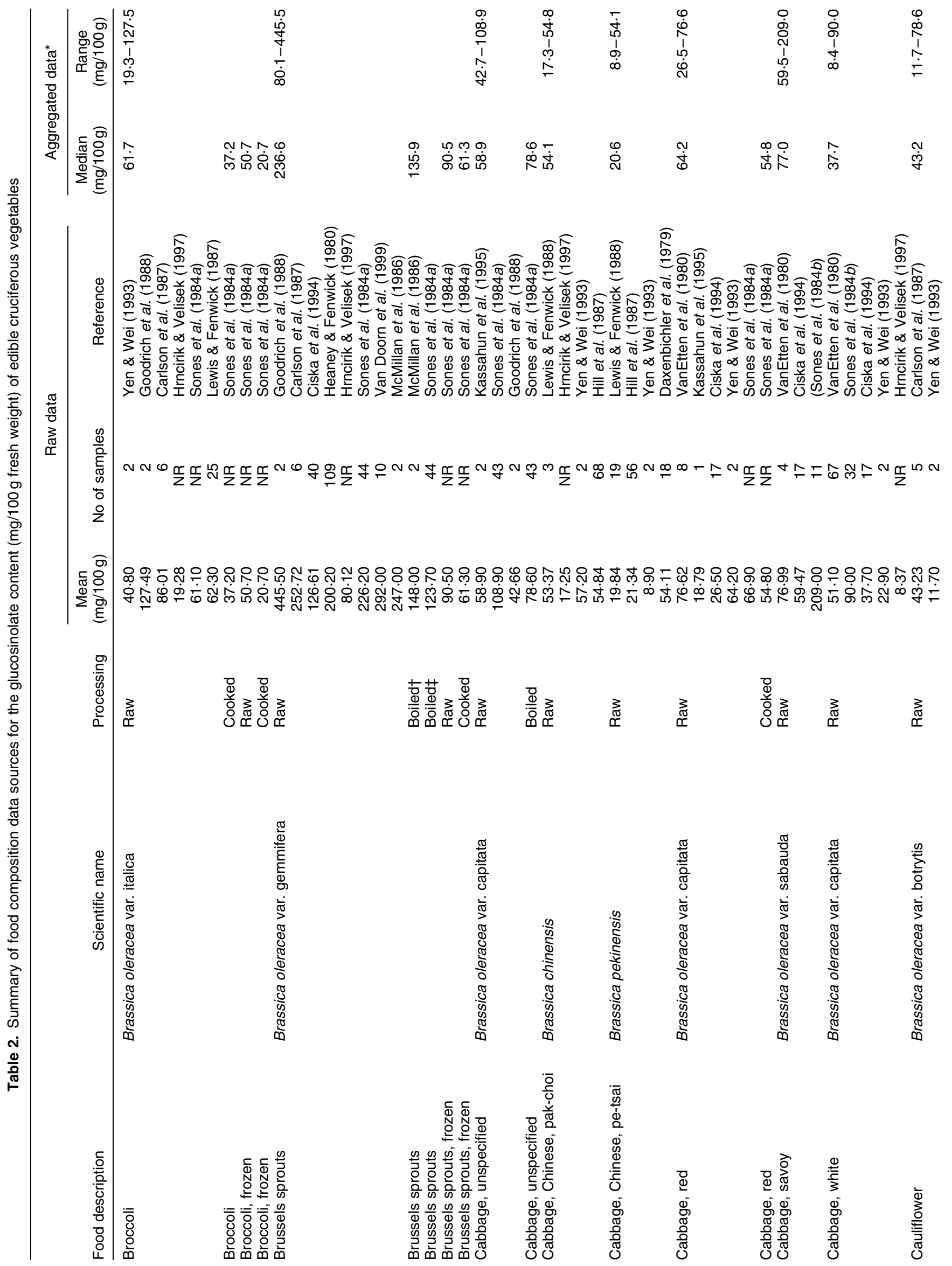




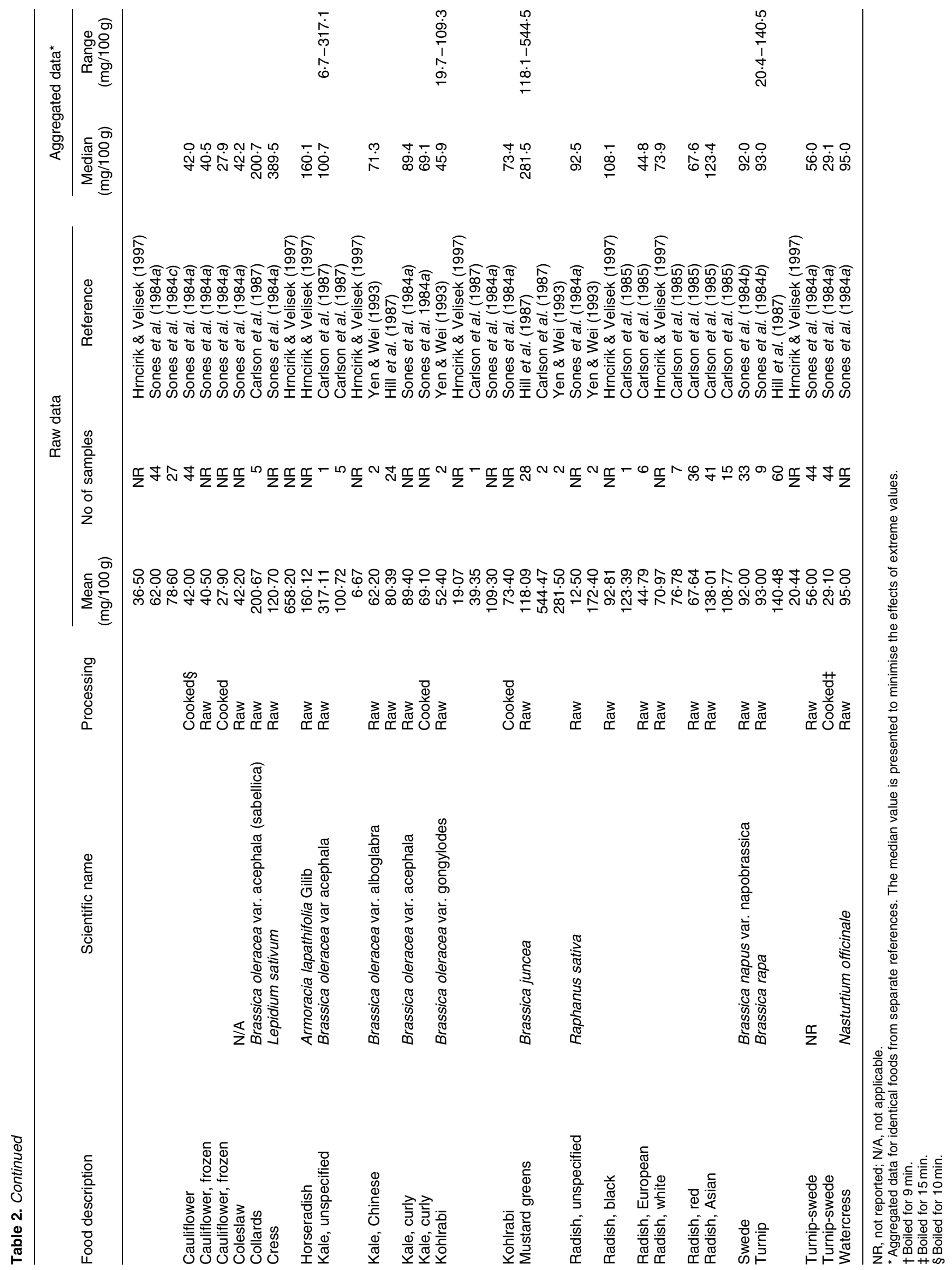


Table 3. Effect of cooking on the glucosinolate content ( $\mathrm{mg} / 100 \mathrm{~g}$ fresh weight) of cruciferous vegetables

\begin{tabular}{|c|c|c|c|c|}
\hline Food description & Reference & Processing & $\begin{array}{l}\text { Total glucosinolate } \\
\text { content }\end{array}$ & $\begin{array}{c}\text { Percentage } \\
\text { decrease }\end{array}$ \\
\hline Broccoli & Sones et al. (1984a) & $\begin{array}{l}\text { Raw } \\
\text { Cooked }\end{array}$ & $\begin{array}{l}61 \cdot 1 \\
37 \cdot 2\end{array}$ & $39 \cdot 1$ \\
\hline Broccoli, frozen & Sones et al. (1984a) & $\begin{array}{l}\text { Raw } \\
\text { Cooked }\end{array}$ & $\begin{array}{l}50.7 \\
20.7\end{array}$ & $59 \cdot 2$ \\
\hline Brussels sprouts & McMillan et al. (1986) & $\begin{array}{l}\text { Raw } \\
\text { Boiled* }\end{array}$ & $\begin{array}{l}247 \cdot 0 \\
148 \cdot 0\end{array}$ & $40 \cdot 1$ \\
\hline & Sones et al. (1984a) & $\begin{array}{l}\text { Raw } \\
\text { Boiled } †\end{array}$ & $\begin{array}{l}226 \cdot 2 \\
123 \cdot 7\end{array}$ & $45 \cdot 3$ \\
\hline Brussels sprouts, frozen & Sones et al. (1984a) & $\begin{array}{l}\text { Raw } \\
\text { Cooked }\end{array}$ & $\begin{array}{l}90.5 \\
61.3\end{array}$ & $32 \cdot 3$ \\
\hline Cabbage & Sones et al. (1984a) & $\begin{array}{l}\text { Raw } \\
\text { Boiled } \neq\end{array}$ & $\begin{array}{r}108 \cdot 9 \\
78 \cdot 6\end{array}$ & $27 \cdot 8$ \\
\hline Cabbage, red & Sones et al. (1984a) & $\begin{array}{l}\text { Raw } \\
\text { Cooked }\end{array}$ & $\begin{array}{l}66 \cdot 9 \\
54 \cdot 8\end{array}$ & $18 \cdot 1$ \\
\hline Cauliflower & Sones et al. (1984a) & $\begin{array}{l}\text { Raw } \\
\text { Boiled } \ddagger\end{array}$ & $\begin{array}{l}62 \cdot 0 \\
42 \cdot 0\end{array}$ & $32 \cdot 3$ \\
\hline Cauliflower, frozen & Sones et al. (1984a) & $\begin{array}{l}\text { Raw } \\
\text { Cooked }\end{array}$ & $\begin{array}{l}40.5 \\
27.9\end{array}$ & $31 \cdot 1$ \\
\hline Kale, curly & Sones et al. (1984a) & $\begin{array}{l}\text { Raw } \\
\text { Cooked }\end{array}$ & $\begin{array}{l}89 \cdot 4 \\
69 \cdot 1\end{array}$ & $22 \cdot 7$ \\
\hline Kohlrabi & Sones et al. (1984a) & $\begin{array}{l}\text { Raw } \\
\text { Cooked }\end{array}$ & $\begin{array}{r}109 \cdot 3 \\
73 \cdot 4\end{array}$ & $32 \cdot 8$ \\
\hline Turnip-swede & Sones et al. (1984a) & $\begin{array}{l}\text { Raw } \\
\text { Boiled } \dagger\end{array}$ & $\begin{array}{l}56 \cdot 0 \\
29 \cdot 1\end{array}$ & $48 \cdot 0$ \\
\hline
\end{tabular}

Individual publications stated that vegetables were boiled for: * $9 \mathrm{~min}, \dagger 15 \mathrm{~min}, ~ \ddagger 10 \mathrm{~min}$.

vegetables such as cauliflower or broccoli rather than cabbage or kale (Nugon-Baudon \& Rabot, 1994). Compilation of the glucosinolate composition data for the individual vegetables allows for these differences in consumption to be considered. Second, the consumption of cruciferous vegetables is probably correlated with the intake of total vegetables and, as yet, most studies have not determined whether the observed effects are due to cruciferous vegetables specifically or due to the intake of vegetables generally (Verhoeven et al. 1996; Van Poppel et al. 1999). Third, cruciferous vegetables contain a range of potentially cancer-protective dietary factors, other than glucosinolates, such as vitamins, minerals and fibre (Nestle, 1998). Use of cruciferous vegetable intake as the exposure measure captures intake of all of these dietary factors and prevents the identification of the specific factors that provide protection.

This is the first attempt to collate the existing published scientific data on the glucosinolate content of foods. At this time there is a relative lack of data on the glucosinolate content of cruciferous vegetables and consequently data from different countries must be aggregated and adequate region-specific data are not available. Research in this field is ongoing and it is probable that additional data on the glucosinolate content will become available. As these studies become available, this database will need to be reviewed and updated. Similarly, further research into the importance of specific glucosinolate compounds will require their inclusion into food composition databases. These data serve as an interim measure in the quantification of dietary exposure to the biologically active constituents of cruciferous vegetables. These data will allow the quantification of intakes that can be used to investigate the role of cruciferous vegetables in cancer aetiology and prevention.

\section{References}

Armstrong BK, White E \& Saracci R (1992) Principles of Exposure Measurement in Epidemiology. New York, NY: Oxford University Press.

CAB International (2000) CAB Abstracts. 1984-2000. Wallingford, Oxon: $C A B$ International.

Carlson DG, Daxenbichler ME \& VanEtten CH (1985) Glucosinolates in radish cultivars. J Am Soc Hort Sci 110, 634-638.

Carlson DG, Daxenbichler ME, VanEtten CH, Kwolek WF \& Williams PH (1987) Glucosinolates in crucifer vegetables: broccoli, Brussels sprouts, cauliflower, collards, kale, mustard greens, and kohlrabi. J Am Soc Hort Sci 112, 173-178.

Carlson DG, Daxenbichler ME, VanEtten CH, Tookey HL \& Williams PH (1981) Glucosinolates in crucifer vegetables: turnips and rutabagas. J Agric Food Chem 29, 1235-1239.

Ciska E \& Kozlowska H (1998) Glucosinolates of cruciferous vegetables. Pol J Food Nutr Sci 7, 5-22.

Ciska E, Piskula M, Martyniak Przybyszewska B, Waszczuk K \& Kozlowska H (1994) Glucosinolates in various cabbage cultivars grown in Poland. Pol J Food Nutr Sci 3, 119-126.

Conran C, Conran T \& Hopkinson S (1997) The Conran Cookbook. London: Conran Octopus.

Crews H, Alink G, Andserson R, et al. (2001) A critical assessment of some biomarker approaches linked with dietary intake. Br J Nutr 86, S5-S35.

Daxenbichler ME, VanEtten CH \& Williams PH (1979) Glucosinolates and derived products in cruciferous vegetables. Analysis of 14 varieties of Chinese cabbage. J Agric Food Chem 27, 34-37.

De Groot AP, Willems MI \& De Vos RH (1991) Effects of high 
levels of brussels sprouts in the diet of rats. Food Chem Toxicol 29, 829-837.

Dekker M, Verkerk R \& Jongen WMF (2000) Predictive modelling of health aspects in the food production chain: a case study on glucosinolates in cabbage. Trends Food Sci Technol 11, 174-181.

De Vos RH \& Blijleven WGH (1988) The effect of processing conditions on glucosinolates in cruciferous vegetables. Z Lebensm Unters Forsch 187, 525-529.

Fenwick GR, Heaney RK \& Mullin WJ (1983) Glucosinolates and their breakdown products in food and food plants. Crit Rev Food Sci Nutr 18, 123-201.

Getahun SM \& Chung FL (1999) Conversion of glucosinolates to isothiocyanates in humans after ingestion of cooked watercress. Cancer Epidemiol Biomarkers Prev 8, 447-451.

Goodrich RM, Parker RS, Lisk DJ \& Stoewsand GS (1988) Glucosinolate, carotene and cadmium content of Brassica oleracea grown on municipal sewage sludge. Food Chem 27, $141-150$.

Griffiths DW, Birch ANE \& Hillman JR (1998) Antinutritional compounds in the Brassicaceae: analysis, biosynthesis, chemistry and dietary effects. J Hort Sci Biotechnol 73, $1-18$.

Hansen M, Laustsen AM, Olsen CE, Poll L \& Sorensen H (1997) Chemical and sensory quality of broccoli (Brassica oleracea L. var italica). J Food Qual 20, 441-459.

Heaney RK \& Fenwick GR (1980) Glucosinolates in Brassica vegetables. Analysis of 22 varieties of Brussels sprouts (Brassica oleracea var. gemmifera). J Sci Food Agric 31, 785-793.

Heaney RK, Fenwick GR \& Sørensen H (1985) Brassica vegetables - a major source of glucosinolates in the human diet. In Advances in the Production and Utilization of Cruciferous Crops. Proceedings of a Seminar in the CEC Programme of Research on Plant Protein Improvement, pp. 40-49. [H Sørensen, editor]. Dordrecht, The Netherlands: Martinus Nijhoff Publishers.

Hill CB, Williams PH, Carlson DG \& Tookey HL (1987) Variation in glucosinolates in Oriental Brassica vegetables. J Am Soc Hort Sci 112, 309-313.

Hrncirik K \& Velisek J (1997) Glucosinolate content of common Brassicaceae family vegetables. Potrav Vedy 15, 161-172.

Hrncirik K, Velisek J \& Davidek J (1998) Comparison of HPLC and GLC methodologies for determination of glucosinolates using reference material. Z Lebensm Unters Forsch 206, 103-107.

Jiao D, Yu MC, Habnkin JH, et al. (1998) Total isothiocyanate contents in cooked vegetables frequently consumed in Singapore. J Agric Food Chem 46, 1055-1058.

Jongen WMF (1996) Glucosinolates in Brassica: occurrence and significance as cancer-modulating agents. Proc Nutr Soc 55, $433-446$.

Kassahun BW, Velisek J, Davidek J \& Hajslova J (1995) The change of cabbage (Brassica oleracea L. var. capitata) glucosinolate content during storage. Potrav Vedy 13, 13-24.

Kushad MM, Brown AF, Kurilich AC, et al. (1999) Variation of glucosinolates in vegetable crops of Brassica oleracea. J Agric Food Chem 47, 1541-1548.

Lewis J \& Fenwick GR (1987) Glucosinolate content of Brassica vegetables: analysis of twenty-four cultivars of calabrese (green sprouting broccoli, Brassica oleracea L. var. botrytis subvar. cymosa Lam.). Food Chem 25, 259-268.

Lewis J \& Fenwick GR (1988) Glucosinolate content of Brassica vegetables - Chinese cabbages Pe-tsai (Brassica pekinensis) and Pak-choi (Brassica chinensis). J Sci Food Agric 45, 379-386.

McDanell R, McLean AE, Hanley AB, Heaney RK \&
Fenwick GR (1988) Chemical and biological properties of indole glucosinolates (glucobrassicins): a review. Food Chem Toxicol 26, 59-70.

McGregor DI, Mullin WJ \& Fenwick GR (1983) Analytical methodology for determining glucosinolate composition and content. J Assoc Off Anal Chem 66, 825-849.

McMillan M, Spinks EA \& Fenwick GR (1986) Preliminary observations on the effect of dietary brussels sprouts on thyroid function. Human Toxicol 5, 15-19.

Mangels AR, Holden JM, Beecher GR, Forman MR \& Lanza E (1993) Carotenoid content of fruits and vegetables: an evaluation of analytic data. J Am Diet Assoc 93, 284-296.

National Food Authority (1995) NUTTAB95: Nutrient Data Table for Use in Australia. Canberra, Australia: Australian Government Publishing Service.

Nestle M (1998) Broccoli sprouts in cancer prevention. Nutr Rev 56, $127-130$.

Nugon-Baudon L \& Rabot S (1994) Glucosinolates and glucosinolate derivatives: implications for protection against chemical carcinogenesis. Nutr Res Rev 7, 205-231.

Peterson J \& Dwyer J (2000) An informatics approach to flavonoid database development. J Food Comp Anal 13, 441-454.

Pillow PC, Duphorne CM, Chang S, et al. (1999) Development of a database for assessing dietary phytoestrogen intake. Nutr Cancer 33, 3-19.

Rand WM, Windham CT, Wyse BW \& Young VR (editors) (1987) Food Composition Data: A User's Perspective. Tokyo, Japan: United Nations University Press.

Reinli K \& Block G (1996) Phytoestrogen content of foods - a compendium of literature values. Nutr Cancer 26, 123-148.

Rodrigues AS \& Rosa EAS (1999) Effect of post-harvest treatments on the level of glucosinolates in broccoli. J Sci Food Agric 79, 1028-1032.

Rogers J (1995) What Food is that? \& How Healthy is it? Sydney, Australia: Lansdowne Publishing.

Rosa EAS \& Heaney RK (1993) The effect of cooking and processing on the glucosinolate content: studies on four varieties of Portuguese cabbage and hybrid white cabbage. J Sci Food Agric 62, 259-265.

Shapiro TA, Fahey JW, Wade KL, Stephenson KK \& Talalay P (1998) Human metabolism and excretion of cancer chemoprotective glucosinolates and isothiocyanates of cruciferous vegetables. Cancer Epidemiol Biomarkers Prev 7, 1091-1100.

Shattuck VI, Kakuda Y, Shelp BJ \& Kakuda N (1991) Chemical composition of turnip roots stored or intermittently grown at low temperature. J Am Soc Hort Sci 116, 818-822.

Shattuck VI \& Wang W (1994) Growth stress induces glucosinolate changes in pakchoy (Brassica campestris ssp. chinensis). Can J Plant Sci 74, 595-601.

Sones K, Heaney RK \& Fenwick GR (1984a) An estimate of the mean daily intake of glucosinolates from cruciferous vegetables in the UK. J Sci Food Agric 35, 712-719.

Sones K, Heaney RK \& Fenwick GR (1984b) The glucosinolate content of UK vegetables - cabbage (Brassica oleracea), swede (B. Napus) and turnip (B. capestris). Food Addit Contam 1, 289-296.

Sones K, Heaney RK \& Fenwick GR (1984c) Glucosinolates in Brassica vegetables Analysis of twenty-seven cauliflower cultivars (Brassica oleracea L. var. botrytis subvar. cauliflora DC). J Sci Food Agric 35, 762-766.

Steinmetz KA \& Potter JD (1991) Vegetables, fruit and cancer. II. Mechanisms. Cancer Causes Control 2, 427-442.

Talalay P \& Fahey JW (2001) Phytochemicals from cruciferous plants protect against cancer by modulating carcinogen metabolism. J Nutr 131, 3027S-3033S. 
Tiedink HGM, Davies JAR, Van Broekhoven LW, Van Der Kamp HJ \& Jongen WMF (1988) Formation of mutagenic $\mathrm{N}$-nitroso compounds in vegetable extracts upon nitrite treatment: a comparison with the glucosinolate content. Food Chem Toxicol 26, 947-954.

United States Department of Agriculture (1998) USDA-NCC Carotenoid Database for U.S. Foods. http://www.nal.usda.gov/ fnic/foodcomp/Data/car98/car98.html

United States Department of Agriculture and Iowa State University (2000) Database on the Isoflavone Content of Foods, Release 1.1. Nutrient Data Laboratory Homepage. http://www. nal.usda.gov/fnic/foodcomp/Data/isoflav/isoflav.html

United States National Library of Medicine (2000) Medline. 1966-2000. Bethesda, MD: United States National Library of Medicine.

Van Doorn HE, Van Der Kruk GC \& Van Holst GJ (1999) Large scale determination of glucosinolates in Brussels sprouts samples after degradation of endogenous glucose. J Agric Food Chem 47, 1029-1034.

VanEtten CH, Daxenbickler ME, Tookey HL, Kwolek WF, Williams PH \& Yoder OC (1980) Glucosinolates: Potential toxicants in cabbage cultivars. J Am Soc Hort Sci 105, 710-714.

Van Poppel G, Verhoeven DT, Verhagan H \& Goldbohm RA (1999)
Brassica vegetables and cancer prevention: Epidemiology and mechanisms. Adv Exp Med and Biol 472, 159-168.

Verhoeven DT, Goldbohm RA, van Poppel G, Verhagen H \& van den Brandt PA (1996) Epidemiological studies on brassica vegetables and cancer risk. Cancer Epidemiol Biomarkers Prev 5, $733-748$.

Verhoeven DTH, Verhagan H, Goldbohm RA, Van der Brandt PA \& Van Poppel G (1997) A review of mechanisms underlying anticarcinogenicity by brassica vegetables. Chem Biol Interact 103, 79-129.

Verkerk R, Dekker M \& Jongen WMF (2001) Post-harvest increase of indolyl glucosinolates in response to chopping and storage of Brassica vegetables. J Sci Food Agric 81, 953-958.

Verkerk R, Van der Gaag MS, Dekker M \& Jongen WM (1997) Effects of processing conditions on glucosinolates in cruciferous vegetables. Cancer Lett 114, 193-194.

World Cancer Research Fund (1997) Food, Nutrition and the Prevention of Cancer: A Global Perspective. Washington, DC: American Institute for Cancer Research.

Yen GC \& Wei QK (1993) Myrosinase activity and total glucosinolate content of cruciferous vegetables, and some properties of cabbage myrosinase in Taiwan. J Sci Food Agric 61, 471-475. 